\title{
RECENT MODIFICATIONS IN THE CONSTRUCTION OF PLATINUM RESISTANCE THERMOMETERS
}

\author{
By T. S. Sligh, Jr.
}

\section{ABSTRACT}

After a brief résumé of some phases of platinum resistance thermometry a description is given of some recent modifications in the construction of resistance thermometers as regards the heads, leads, terminals, and sealing of the strain-free type. The elimination of the drying head and the use of an all-metal case with the calorimetric type of resistance thermometer are also discussed. The necessity for relieving strains in the winding of the latter type is shown, and means of accomplishing this are pointed out.

Some practical notes regarding the construction of resistance thermometers and a description of the construction of a convenient and effective form of laboratory heating coil are given.

\section{CONTENTS}

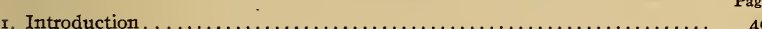

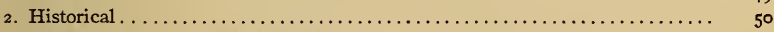

3. Resistance-temperature relations. . . . . . . . .

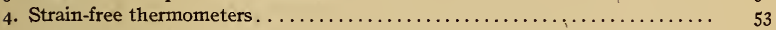

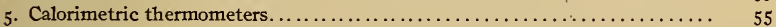

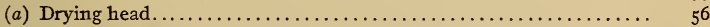

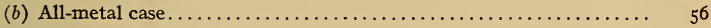

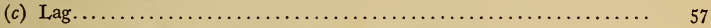

6. Materials and methods for thermometer construction $\ldots \ldots \ldots \ldots \ldots \ldots \ldots .57$

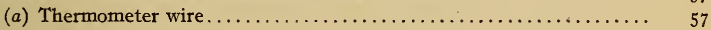

(b) Leads. . . . . . . . . . .

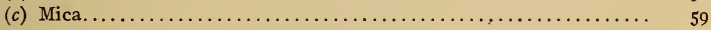

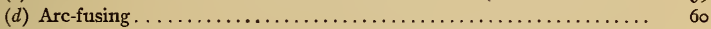

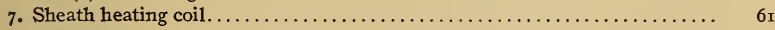

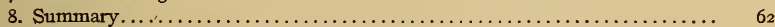

\section{INTRODUCTION}

During the past six or eight years in the process of testing commercial thermometers and constructing thermometers for use at this Bureau a number of modifications in the construction of resistance thermometers have been made. Some of these are desirable on account of the accuracy to be gained, others for the simplification of construction, increased mechanical strength, etc. 
It now seems well to describe these modifications representing the present practice of this Bureau, indicating the reasons for such changes as have been made from former practice. However, extended experimental evidence is beyond the scope of this paper and will not be dealt with here as such.

\section{HISTORICAL}

Since the failure of the original proposal of Siemens ${ }^{1}$ of a platinum resistance thermometer having the coil wound on a clay cylinder and protected by an iron tube, nearly all successful forms of resistance thermometers have been constructed with the coil wound on mica, as proposed by Callendar, ${ }^{2}$ with a protecting tube of glass, porcelain, or quartz. Heraeus introduced a thermometer in which the winding is sealed into quartz, but this form, although used with some success for industrial work, is not fitted for exact work on account of its unstable resistance, naturally resulting from the stress to which the winding must be subjected. Jaeger and von Steinwehr ${ }^{3}$ have described a thermometer consisting of a silk insulated wire protected by a.metal capillary tube, but this thermometer exhibited thermal after effects similar to those shown by the mercury-in-glass thermoineter. Numerous forms of thermometers have been made in which glass and other materials were used to support and insulate the winding, notably by E. H. Griffiths. ${ }^{4}$ None of these forms, with the exception of the Callendar mica cross, have come into general use. Dickinson and Mueller ${ }^{5}$ described a calorimetric platinum resistance thermometer in which the wire was wound on a strip of mica which was inclosed in a flat closely fitting metal sheath between thin plates of mica.

Three methods of compensating for or eliminating the effects of the resistance of the thermometer leads and terminal contacts which have been in general use are the Siemens three-lead method, the Callendar compensating-loop method, and the potential-terminal method. Measurements with the last-named method may be made by the use of a potentiometer and current-measuring shunt, a Thompson bridge, by the Kohlrausch differential galvanometer method, or by the use of a Wheatstone bridge ${ }^{6}$ and reversing commutator, as is the practice at this Bureau. Measure-

\footnotetext{
1 Proc. Roy. Soc., 19, p. 351; 1871.

2 Phil. Mag., 32, p. x04; $189 \mathrm{r}$.

${ }^{3}$ Zs. für Instrk., 26, p. 237; 1906.

4 Phil. Trans., A, 182, pp. 43-72; 1891.

${ }^{5}$ B. S. Bulletin, 9, p. 483 ; $19{ }^{13}$. B. S. Sci. Papers, No. 200.

'E. F. Mueller, B. S. Bull., 13, p. 547; 1917.
} 
ments of the resistance of a potential-terminal thermometer by any of these methods are independent of the lead and terminalcontact resistances, while the indications of the three-lead and compensating-loop thermometers are not wholly independent of these resistances.

\section{RESISTANCE TEMPERATURE RELATIONS}

As the result of the large amount of experimental work which has been done with the platinum resistance thermometer since the appearance of Callendar's original work ${ }^{7}$ it is known that in the interval $-40^{\circ}$ to $\mathrm{I} 100^{\circ} \mathrm{C}$ the relation between the resistance, $R$, and the temperature, $t$, of a platinum resistance thermometer can be very accurately represented by a parabolic equation of the form

$$
R=R_{o}\left(\mathrm{I}+\alpha t+\beta t^{2}\right) .
$$

For purposes of computation this may be put in the more convenient form proposed by Callendar, which involves the use of two formulas, one of which introduces the very convenient concept of platinum temperatures $(p t)$ which are related to resistances by the equation

$$
p t=\mathrm{IOO} \frac{R_{\mathrm{t}}-R_{\mathrm{o}}}{F I}
$$

where $R_{\mathrm{t}}$ is the resistance of the thermometer at $t^{\circ} \mathrm{C}, R_{\mathrm{o}}$ is the resistance at $0^{\circ} \mathrm{C}$, and $F I$, the fundamental interval, is $R_{100}-R_{0}$. Thus the platinum temperature is a linear function of the resistance of the thermometer.

The fundamental coefficient, $c$, of the thermometer wire is defined by the relation

$$
c=\frac{R_{100}-R_{\mathrm{o}}}{\mathrm{IOO} R_{\mathrm{o}}}
$$

and serves, as explained below, as a criterion of the purity of the platinum.

For the reduction of platinum temperatures to ${ }^{\circ} \mathrm{C}$ use is made of the difference formula $t-p t=\delta(\mathrm{I}-t / \mathrm{IOO}) t / \mathrm{I} 00$ where $\delta$ is a constant of the thermometer wire and is determined by a measurement of resistance at some temperature in addition to $0^{\circ} \mathrm{C}$ or $100^{\circ} \mathrm{C}$. Where the construction of the thermometer permits the boiling point of sulphur ( $\left.\mathrm{SBP}=444.6^{\circ} \mathrm{C}\right)$ is used for the deter- 
mination of $\delta$. The Callendar formulas are reducible to the form $R t=R_{\mathrm{o}}\left(\mathrm{I}+\alpha t+\mathrm{B} t^{2}\right)$ by means of the relations,

$$
\alpha=c\left(\mathrm{I}+\frac{\delta}{\mathrm{IOO}}\right) \text { and } \mathrm{B}=\frac{c \delta}{(\mathrm{IOO})^{2}},
$$

where the symbols have the meanings stated previously.

The scale of temperature defined by a thermometer of pure platinum calibrated at the ice point, the steam point, and the sulphur boiling point has been adopted as the standard scale in the interval $-40^{\circ} \mathrm{C}$ to $45^{\circ} \mathrm{C}$. Even at temperatures up to I $100^{\circ} \mathrm{C}$ this scale is found to agree with the thermodynamic scale of temperature to the accuracy with which that scale can be realized by the use of the gas thermometer.

Pure platinum has a fundamental coefficient, $c=0.0039+$, and a delta value, $\delta=1.5-$. The impurities usually associated with platinum tend to lower the value of $c$ and to increase the value of the SBP $\delta$. Further, thermometers of impure platinum when calibrated in the usual manner have been found to define a temperature scale which differs somewhat from the standard scale. ${ }^{8}$

The several national laboratories which use the platinum resistance thermometer to define the standard scale in the interval $-40^{\circ} \mathrm{C}$ to $45^{\circ} \mathrm{C}$ are in agreement in specifying that the purity of the platinum employed for thermometer construction is determined by the mean temperature coefficient of resistance in the interval $o$ to $100^{\circ} \mathrm{C}$, which coefficient should not be less than 0.00388 , and by the value of the constant, $\delta$, in the Callendar difference formula, which value ${ }^{9}$ should not be greater than $1.5^{2}$. These specifications should be understood to refer to wire which is pure, perfectly annealed, and free from strain. Some experimental work now nearing completion at this Bureau indicates that strain may affect the constants of thermometer wire, the effect being a lowering of the fundamental coefficient and also a lowering of the value of $\delta$. Furthermore, there is some evidence that a thermometer wound of pure platinum wire in a strained condition does not define exactly the same scale as does a thermometer wound of the same wire free from strain, though the difference is negligible in the range $o$ to $100^{\circ} \mathrm{C}$ for thermometers which by comparison with a strain-free standard at $30^{\circ} \mathrm{C}$ show a

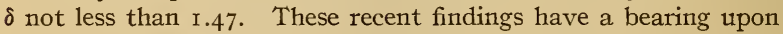
some modifications in the construction of calorimetric resistance thermometers, which will be discussed later in this paper.

8 Waidner and Burgess, B. S. Bull. 6, p. $150,1909$.

${ }^{9}$ Waidner, Mumer, and Foote, Bull. Am. Inst. Min. and Met. Eng., pp. 2051-2063; September, 1919. 


\section{STRAIN-FREE THERMOMETERS}

During the progress of some earlier work at this Bureau the accuracy attainable at high temperatures was limited by the fact that the constants of the thermometers used were changed by exposure to such temperatures. These changes were attributed to possible contamination of the thermometer wire by the hot mica and to the straining of the wire due to changes in volume of the mica supports; accordingly a mounting was devised $(E$, Figs. I and 2), which supported the winding in such a manner as to give a minimum of contact with the mica form and to preclude the setting up of strains in the winding due to swelling of the mica.

For this strain-free mounting two rows of holes spaced $0.6 \mathrm{~mm}$ from center to center are drilled or puriched about $0.5 \mathrm{~mm}$ from the edges of a strip or core of mica (a, Fig. 2) $8 \mathrm{~mm}$ wide and o.I $\mathrm{mm}$ thick. A similar row of holes is punched in each of two mica strips or fins (b, Fig. 2) $2 \mathrm{~mm}$ wide by $0.1 \mathrm{~mm}$ thick. This core, with the fins lined up with the holes in its edges, is clamped between the two halves of a split mandrel $(C$, Fig. I) $7 \mathrm{~mm}$ in diameter, and the winding is passed around the mandrel and through the holes. When the winding is completed the mandrel is carefully removed and the fins displaced through $90^{\circ}$ so as to space the winding.

A simpler strain-free mounting which is probably as effective as the above was proposed by H. C. Dickinson of this Bureau in I 916 and has since been used by one of the manufacturers of resistance thermometers in this country. This construction makes use of the mica cross as in the Callendar mounting but substitutes deep narrow slots for the V-shaped notches for the winding. The winding is put on over a quartered mandrel whose diameter is slightly greater than the root diameter of the slots.

A modification of this mounting which would seem to line the coil up better consists in cutting the slots in one arm of the cross with a root diameter equal to the diameter of the mandrel and the slots in the other arm a few tenths of a millimeter deeper. Thus when the winding is put on and the mandrel removed the wire is supported on the bottoms of the shallower slots and on the edges of the deeper ones.

After the winding is put on the mounting, the short platinum leads (the branch terminals) are passed through small holes in the upper end of the mica core and are arc-welded to the ends of the gold internal leads, which are anchored through holes in two short 
strips of mica. These lead anchorages are secured to the core by two small platinum clamps (c, Fig. 2). 'The gold leads are insulated from each other for about ro $\mathrm{cm}$ above the thermometer "bulb" by mica washers (e, Fig. 2) spaced $5 \mathrm{~mm}$ apart and only a trifle smaller in diameter than the tube into which the thermometer is to be placed. These washers serve to reduce the convection currents in the thermometer tube which would tend to lower the temperature of the thermometer when used in a hot bath. The mica washers are punched from o.r $\mathrm{mm}$ mica, and four small holes are punched for the leads. Two of these holes, opposites, are spaced about half as far from the center of the washer as are the other two holes. The washers are put on the leads staggered, that is, a given lead will be passed through one of the inner holes in one washer and through an outer hole in the next, etc., thus putting a slight bend in the lead at each washer which serves to keep the washers spaced. (This method of punching and mounting the washers was devised by H. K. Griffin of this Bureau.) Glass capillary tubes ( $p$, Fig. I) serve to insulate the remainder of the internal leads.

The thermometer with its leads is now slipped into a closely fitting glass, porcelain, or quartz tube, and the leads are brought out of the tube around a small glass evacuating tube ( $f$, Fig. $r$ ) which is then cemented in place with De Khotinsky cement. \The thermometer is thoroughly dried by evacuating and washing out the tube with air which has been passed through a drying tube, and the evacuating tube is sealed off with dry air in the thermometer tube, or with hydrogen if the thermometer is to be used at very low temperatures.

A winding of this type of $0.1 \mathrm{~mm}$ wire will dissipate the heat generated by a current of $\mathrm{r} .5$ milliamperes in the winding with a temperature rise of about $0.00 \mathrm{I}^{\circ} \mathrm{C}$.

The head, the construction of which is shown in Fig. $\mathrm{r}$, is slipped onto the tube from the bottom, and is cemented or secured to the tube by a wrapping of shellacked silk thread ( $g$, Fig. I). This latter method permits of easy removal of the head. The internal leads are now arc-fused to short gold wires which have been silver-soldered to the copper studs in the thermometer head. The flexible leads $(J$, Fig. $r$ ), which are soft-soldered to the terminal studs, consist of four strands insulated and covered with a braid, each strand consisting of three No. 28 enameled copper wires double-silk covered, twisted together, and again double-silk covered. This lead was designed to eliminate the variable lead 
Scientific Papers of the Bureau of Standards, Vol. 17

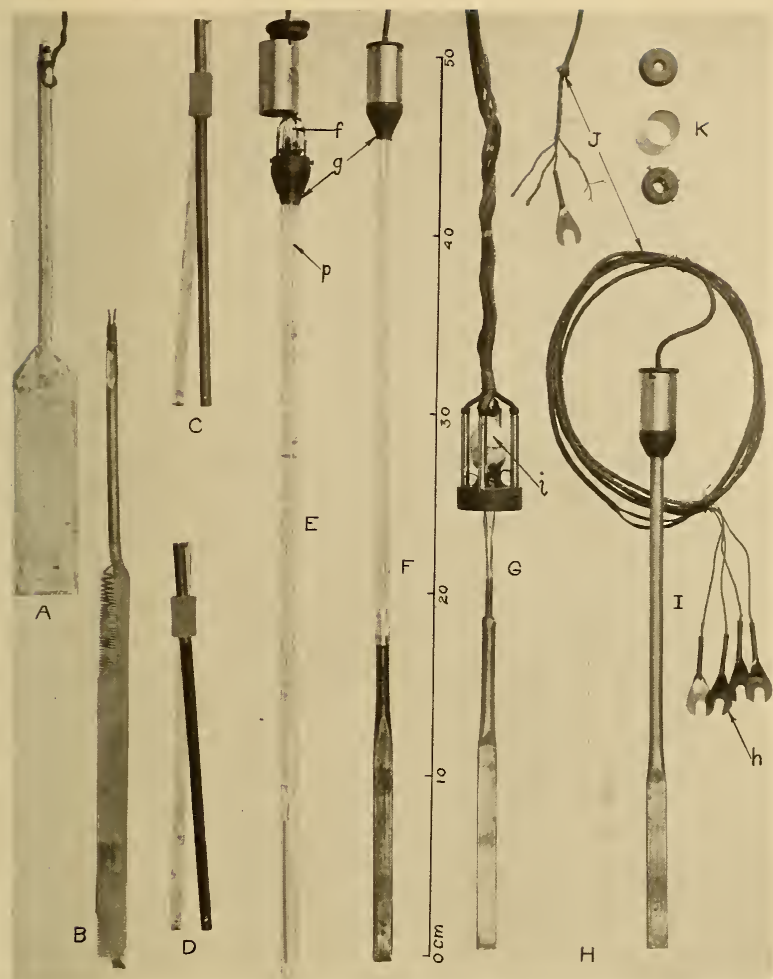

FIG. I.-Sheath type heating coils, core mandrels, and various types of resistance thermometers

$A$, Sheath heating coil. Capacity, 600 watts, with a loading of ro watts $/ \mathrm{cm}^{2}$ of surface

$B$, Sheath heating coil sectioned. Note that copper leads are flattened and wound for a few turns on the core before joining the resistance winding. Leads are insulated by mica. Cap is of bakelite cemented to the lead duct

$C$, Smooth mand rel on which strain-f ree coils are wound

$D$. Threaded mandref for notching calorimetric cores

$E$, Standard strain-free thermometer B. S. No. $\mathrm{C}_{22}$. Only about $10 \mathrm{~cm}$ of mica washers are needed instead of the $25 \mathrm{~cm}$ shown here

$F$, Calorimetric thermometer B. S. No. $\mathrm{Pt}_{7}$ for use at temperatures up to $500^{\circ} \mathrm{C}$. Method of sealing tuhe and at taching leads in head as shown at $f$

$G$, Commercial form of calorimet ric resistance thermometer

$G$, Commercial form of calorimet ric resistance thermometer
$H$, Calorimetric winding showing gold leads and side-plates

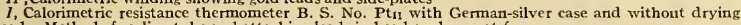
head. Method of sealing tube and attaching leads in head as shown at $f$

$J$. Flexible lead for resistance thermometers

$K$, New style thermometer head of the size shown at $F$ and $I$. Head at $E$ is of a slightly larger size 
Scientific Papers of the Bureau of Standards, Vol. 17

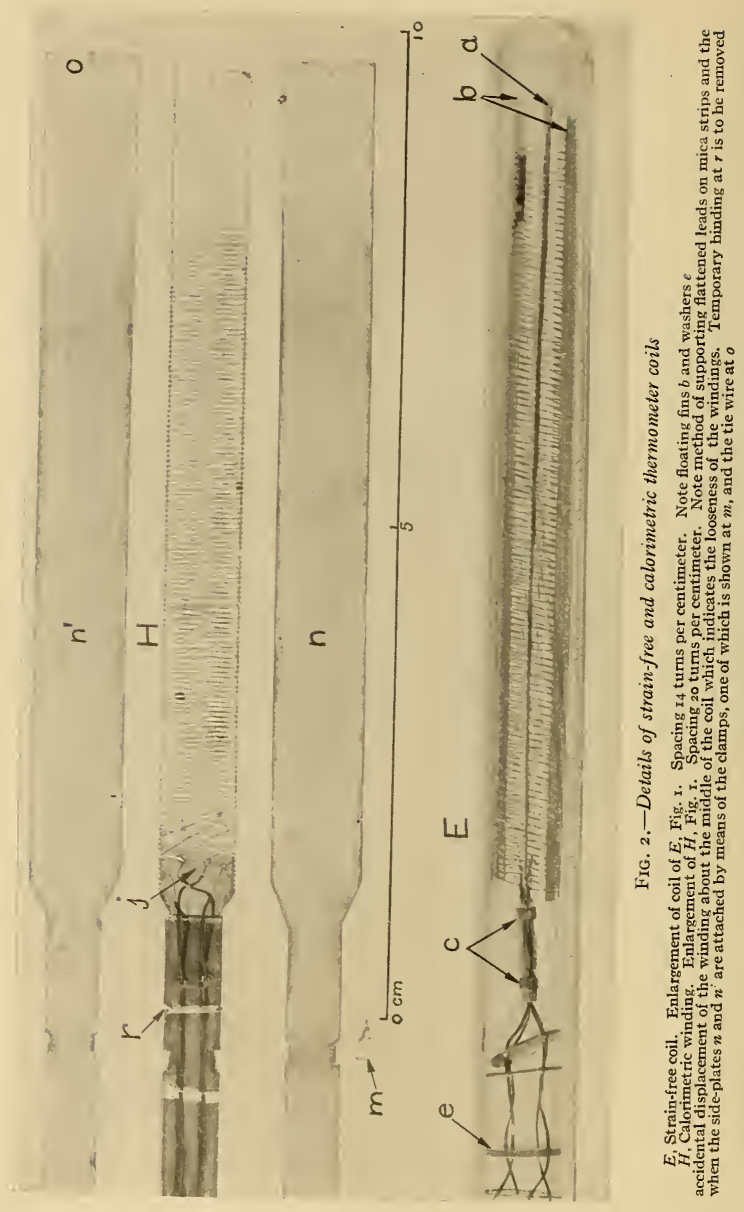


resistance so often experienced with lamp-cord flexibles due to the slip resistance of one or more strands which have become broken or were not originally properly soldered to the terminals.

The light copper terminals ( $h$, Fig. I) are cut from $0.2 \mathrm{~mm}$ sheet copper, and owing to their small heat capacity and good thermal conductivity, tend to minimize troublesome thermal electromotive forces at the commutator or bridge terminals. A thin gold plating will prevent oxidation and insure good electrical contact at the binding posts.

\section{CALORIMETRIC THERMOMETERS}

This type of thermometer was developed at this Bureau by Dickinson and Mueller. ${ }^{10}$ A detailed description of the original construction is given in the reference cited.

Since the construction of the commercial form ( $G$, Fig. I) of these thermometers precludes their use at temperatures above about $150^{\circ} \mathrm{C}$, it has been the practice at this Bureau to calibrate them by observations in ice and in steam and to determine their delta by comparison at $30^{\circ} \mathrm{C}$ with a strain-free thermometer which had been calibrated at ice, steam, and at the SBP.

These thermometers showed values of $\delta$ of about 1.47 both when calibrated against the strain-free thermometers and against the verre-dur mercury-in-glass standards of the Bureau. Later some thermometers of the calorimetric type $(F$, Fig. I) were constructed with platinum sheaths sealed to long glass stems and were calibrated at ice, steam, and at the SPB. These thermometers were then compared with the strain-free thermometers at lower temperatures and the results previously mentioned; that is, the lowering of the $\delta$ value by mechanical strain, were arrived at. This led to the construction of coils very loosely wound on thick $(0.5 \mathrm{~mm})$ mica cores, thoroughly annealed before and after winding by passing an electric current through the wires. These coils were placed in sheaths which were lightly flattened down on the windings and fused at the bottoms. The thermometers were then annealed by flashing the coils on a voltage of $\mathrm{I}_{20-\mathrm{I}} 50$ volts, care being taken not to overheat the mica. (The temperature of the wire calculated from voltmeter and ammeter readings was about $1000^{\circ} \mathrm{C}$.) These thermometers were then finished as described for the strain-free type.

Thermometers so constructed, with special care taken both to avoid the introduction of strains in construction and to anneal the thermometer thoroughly after incasing, compare very favor- 
ably with the strain-free type, showing a value of $\delta$ which approaches 1.49. Further, the temperature scale defined by these thermometers is, within the limits of accuracy of the comparison of platinum resistance thermometers, identical with that defined by the strain-free type thermometers.

(a) Drying Head.-The glass drying head (i, Fig. I) used on the original calorimetric type of thermometers has been eliminated in this latter design because it has now been found easy to secure tubing for the sheaths which is free from flaws, and the technique of construction has been developed to a point where the joints can be made permanently tight and the thermometer and case thoroughly dried before sealing.

(b) All-Metal Case.-With the elimination of the drying head it seemed worth while to go a step further toward a robust construction by eliminating the glass stem between the sheath and the thermometer head. German silver was selected for the sheath ( $I$, Fig. I) on account of its low thermal conductivity, its freedom from excessive oxidation, and its availability in the desired form. It is evident that any metal of low thermal conductivity, if not subject to corrosion, could be used. As a matter of fact there are several such metals which are superior to German silver in some respects, but they are not at present available in the form of thinwalled tubing. For use in chemical reagents the sheath could well be made of platinum or some of its alloys, the latter having in general the advantages of greater stiffness and lower thermal conductivity.

The case is made of tubing $30 \mathrm{~cm}$ long by $0.75 \mathrm{~cm}$ diameter by $0.02 \mathrm{~cm}$ thick, flattened over a brass strip or form $0.1 \mathrm{~cm}$ thick for a length of about $15 \mathrm{~cm}$. The coil, head, and external leads are as described above.

The internal leads consist of four No. 30 copper wires with silk and enameled insulation; these are stripped of insulation for about $4 \mathrm{~cm}$ of their length and rolled to a width of $\mathrm{I} \mathrm{mm}$. To these flattened ends short lengths $(5 \mathrm{~mm})$ of gold wire are silver soldered, and this wire is arc soldered to the ends of the winding. The flattened portions of the leads are laid between thin strips of mica and fastened by clamps ( $M$, Fig. 2) to the mica core and the mica side plates, and the coil is slipped into the sheath from the bottom; the insulated ends of the leads are cabled and led out of the end of the tube through a collar of bakelite and around a glass evacuating tube as in the strain-free construction ( $f$, Fig. 1 ). The sheath is now flattened down lightly on the coil and on the mica- 
covered portion of the leads and the end of the sheath silver soldered. This soldering may be accomplished without injury to the mica if the core terminates about $8 \mathrm{~mm}$ above the bottom of the sheath, and the sheath is clamped lightly in a vise at this point to conduct the heat from the winding.

The winding is again flashed as described above. The evacuating tube is then plugged temporarily with cement, and the thermometer immersed in a tube of water from the surface of which the atmospheric pressure is removed by a suction pump. Any leaks can then be located by means of the air bubbles which will form. If the thermometer is tight the evacuation tube is sealed off, and the thermometer tube is fitted to the head, secured with a small set screw, and the internal and external leads soldered to the terminal studs.

It has been found that no effect of stem conduction can be detected when the thermometer bulb is immersed in the ice bath to a point a little above the flattened portion. This immersion is about that required for the glass-stem type. The same immersion appears sufficient in the steam bath.

(c) LAG.-The use of thicker core plates and lighter sheath pressures together with the all-metal case entails some sacrifice as regards rapidity of action; that is, the lag of the thermometer is increased, and the current-carrying capacity for a given temperature rise is slightly reduced. However, the sacrifice is slight, as the lag of the thermometers tested including the lag of the galvanometer (period 5 seconds) has been found to be between 2.5 and 3.5 seconds in the ice bath. By lag is meant the number of seconds required for the temperature difference between the thermometer and the bath to be reduced to $\mathrm{I} / e$ of its initial value. The lag could be reduced somewhat by reducing the amount of metal in the case, or by making the stem of a low-conductivity metal and the sheath of a high-conductivity metal, such as copper or silver. However, since lags of the magnitude encountered introduce no complications in the use of these thermometers for the service for which they are designed, the slight possible gain due to the changes mentioned has not appeared to be worth the additional complication of construction.

\section{MATERIALS AND METHODS FOR THERMOMETER CONSTRUCTION}

(a) THERMOMETER WIRE.-Thermometer wire should be of the highest purity platinum, $0.1 \mathrm{~mm}$ diameter serving for most purposes. Smaller wire is more difficult to handle, is more easily 
contaminated, and, while it would seem at first glance that a more compact thermometer could be constructed by its use, the sensitivity of such a thermometer is necessarily reduced on account of the reduced area for the dissipation of heat because the permissible heating by the measuring current is limited. Wire of o.I $\mathrm{mm}$ diameter, calorimetric construction, will dissipate about $0.000003 \mathrm{watt} / \mathrm{cm}$ of length (a current of 5 milliamperes in the winding), with a temperature rise of $0.00 \mathrm{I}^{\circ} \mathrm{C}$.

Heavier wire, 0.2 to $0.4 \mathrm{~mm}$ in diameter, is preferable for work at higher temperatures because the larger wire is more nearly selfsupporting, is less easily contaminated, and because it has been found that low-resistance thermometers $\left(R_{\circ}=2.5 \mathrm{ohms}\right)$ are entirely suitable for work at such temperatures. The wire should be thoroughly annealed before winding by heating to rooo to I $200^{\circ} \mathrm{C}$ by the passage of an electric current, should be wound with as little tension as practicable, and should be as thoroughly annealed after winding as the construction of the thermometer will permit.

With the strain-free coil there is little danger of dehydrating the mica by electrically heating the winding to a temperature of about $1000^{\circ} \mathrm{C}$ with the coil in the open. With the calorimetric construction the wire can be heated to this temperature only momentarily by "flashing" on a high voltage. The annealing is to be secured by a series of flashes, allowing the mica to cool after each flash. This flashing is especially valuable after the sheath has been flattened down on the winding because it tends to ease up any local strains which may have been set up by such flattening.

It has been found convenient to adjust the resistance of the winding so as to give a fundamental interval of approximately either Io or I ohms, which permits rapid and accurate calculations of temperature by the use of the slide rule only.

(b) LEADS.-The internal leads are of gold wire $0.3 \mathrm{~mm}$ in diameter for use up to temperatures of $1000^{\circ} \mathrm{C}$. Gold is selected because of its freedom from oxidation, its low thermal emf against the copper studs in the head, and because it may be readily arcfused to platinum. Internal leads are made of platinum only for use above $1000^{\circ} \mathrm{C}$. Copper leads may be used only below $200^{\circ} \mathrm{C}$.

Thermal conduction along the leads should be shunted to the case in the calorimetric construction by having at least $4 \mathrm{~cm}$ of the internal leads rolled thin and mounted between thin strips of mica in the flattened portions of the sheath. 
With the potential terminal construction for use with a Wheatstone bridge and commutator it is desirable that the two current leads have nearly equal resistances in order that it may be necessary to shift only one or two bridge dials when changing from the "normal" to the "reverse" setting. It is further desirable that the changes in resistance of these leads with changes in temperature be nearly equal. These results may be attained by cutting all four of the branch terminal platinum leads, two current and two potential leads, to the same length and making the remainder of the leads as nearly alike as practicable. When finished there are four possible combinations of leads, of which the best combination may be selected by measurements in the ice bath. In nearly every case it will be possible to so select the combination as to give normal and reverse settings which differ by not more than o.or ohm. By an adjustment similar to the adjustment of the value of $R_{\mathrm{o}}$ these settings have been made alike to within o.oor ohm. It should be noted that this adjustment of leads is merely for convenience and in no way improves the accuracy of measurement. For instance, a constant resistance of Io ohms in one lead would have no effect upon the accuracy of the resistance measurements except as it slightly reduces the galvanometer sensitivity.

(c) Mica.-Clear ruby mica free from iron oxide, which shows up as a brownish stain, should be used for the construction of resistance thermometers. The mica used in the construction of strainfree thermometers should be as thin as can be conveniently worked (o.I $\mathrm{mm}$ or less) in order that the heat capacity and consequently the lag of the thermometer may be reduced. The same is true of the calorimetric thermometer except as regards the central core, which should be about $0.5 \mathrm{~mm}$ thick in order that the wire may not be unduly strained by bending around the thin edges.

Mica may be cut nicely with foot shears such as are used for cutting light sheet metal. If such are not available or if only a narrow strip is to be trimmed off the mica may be clamped between steel straightedges and cut with a safety-razor blade. Small holes may be made with a punch and die (a jeweler's staking tool is convenient for this work), or by drilling with a jeweler's pivot drill or a small drill made of piano wire or a needle. Drilling may be done by hand, in which case a neater hole is secured by drilling from first one side and then the other, or by a high-speed power drill, in which case it is best to back the mica up by a smooth surface such as hard rubber or brass. Notches for the calorimetric winding may be cut by clamping the mica between the two halves 
of a split hardened-steel screw (D, Fig. I) of I4 to 20 threads per centimeter and cutting out the $V$-shaped notches with a hacksaw blade the teeth of which have been ground down to a $V$-shape to fit the threads and slightly rounded on the edge. A smoother cut is secured if the first cut is taken backwards rather than in the usual way. After the notches have been cut loose bits of mica, etc., may be cleaned off by "sawing " a bundle of loose cotton threads across the edge of the mica while it is still clamped in the form. When the core is removed from the form its edges should be beveled slightly on a medium-grit carborundum stone.

Holes for the strain-free winding may be spaced by clamping the mica between one-half of the threaded form and a strip of hard rubber and drilling at the base of the notches. A flexible drill made of $0.2 \mathrm{~mm}$ piano wire is serviceable for this work. Where a row of holes is to be drilled near an edge it is often better to leave about a millimeter extra width on the strip to be trimmed off later between straightedges.

The clamps used for holding the various parts of the mica together in the assembled thermometer are made of platinum wire rolled to strip and annealed. Copper clainps may be used for work at temperatures below about $200^{\circ} \mathrm{C}$.

The side plates $\left(n, n^{\prime}\right.$, Fig. 2$)$ on the calorimetric coil are held in place at the bottom of the winding by a small platinum wire passed through a hole in the plates and the core. (o, Fig. 2.)

(d) ARC-Fusing.- There are two general methods of arc-fusing which are suitable for resistance thermometer work. The twocarbon method, in which an arc is drawn out between two carbons and brought up to the work, is suitable for heavy work such as closing the ends of platinum or silver sheaths or for work with base metals where a flux is necessary. The two-carbon method does not localize the heat so well as the single-carbon method, in which the work to be fused is made the positive pole of a dc arc of which a single carbon is the negative pole. The currents and voltages required vary with the size of the work to be fused. Thirty volts and I ampere are usually sufficient to join two o.I $\mathrm{mm}$ platinum wires. Somewhat larger voltages and currents are required to join the $0.3 \mathrm{~mm}$ gold wire to the winding. No flux is required in the fusing of gold, silver, and platinum.

A convenient method of securing the variable voltages and currents required for this work consists in tapping off through a rheostat from the sliding contact of a 50 -ohm rheostat which is connected across the r ro-volt de mains. 


\section{SHEATH HEATING COIL}

It does not seem out of place in this paper to describe a very effective type of heating coil ( $A$ and $B$, Fig. I) which has been developed at this Bureau for use in baths of stirred liquid. The winding consists of a constantan ribbon rolled from wire of sizes No. 20 to No. 36 , according to requirements, and wound bifilarly on a notched mica strip. The spacing of the notches from center to center is usually made about twice the width of the ribbon.

The notches may be punched, or cut on a form similar, except as regards size and notching, to that used for the calorimetric thermometers, or cut with a small circular saw driven at high speed. In this last case the mica strip should be backed up with a strip of hardwood, or the edge of the saw should be rotating in a slot cut in the edge of a metal strip which serves as a support for the mica. Leads are of copper silver-soldered to the ends of the winding, anchored to the core by being passed through slits and brought out through the lead duct, and insulated by silk or mica strips as seems best.

The winding with sideplates of thin mica is slipped into a case made by flattening a thin-walled copper tube. The sheath is squeezed down tightly on the coil in a vise and the end soldered. The lead duct consists of a smaller tube, round or flattened as is convenient, which has previously been hard-soldered to the sheath.

Hard or silver solder is used in the place of soft solders in the construction of thermometers and heating coils wherever possible because it gives a more permanent union of the parts.

The form of heating coil described has small lag and heat capacity together with large dissipating capacity, which makes it especially adapted for use with thermoregulated baths. Tests of heat dissipation made in stirred water baths indicate a dissipation of $0.07 \mathrm{watt} / \mathrm{cm}^{2}$ of sheath surface for each degree difference in temperature of winding and bath. Thus with a loading of Io watts $/ \mathrm{cm}^{2}$ the temperature of the winding runs about $140^{\circ} \mathrm{C}$ above the temperature of the bath. A loading of $30 \mathrm{watts} / \mathrm{cm}^{2}$, probably the safe maximum value, requires a difference of temperature of $430^{\circ} \mathrm{C}$. Without stirring of the bath the transfer coefficient drops to about $0.05 \mathrm{watt} / \mathrm{cm}^{2}$ for each degree centigrade difference of temperature between winding and bath.

No tests on the rate of transfer in oil baths have as yet been made, but it is known that the coefficient is very much smaller than in water; 0.03 would probably be a safe value. 
These coils are usually wound for a loading of about 10 watts $/ \mathrm{cm}^{2}$ and are tested for leak in a manner similar to that applied to the calorimetric thermometers. It is essential that the coils be sealed against the bath liquid (water), and if used at low temperatures the lead duct should be sealed with De Khotinsky cement or by some other method to prevent the condensation of atmospheric moisture on the winding and consequent almost inevitable shortcircuit.

In conclusion acknowledgement is made of the assistance rendered by $\mathrm{E}$. F. Mueller of this Bureau in the preparation of this paper. The construction of resistance thermometers therein decribed is due to the combined efforts of the members of this Bureau who have worked along these lines during the past few years.

\section{SUMMARY}

The potential terminal type of thermometer is preferred in view of its more complete elimination of lead resistance.

Thermometer leads are now made of four strands, each made up of three No. 28 enameled copper wires. This construction affords sufficient flexibility and avoids the difficulties caused by the breakage of strands and the consequent variable lead resistance which is so often encountered with the fine-strand flexibles.

Thermometer bridge terminals are made of thin sheet copper, which may be gold or silver plated.

A thermometer head of simpler construction and neater appearance than the metal-cased head previously used on the strainfree type of thermometer is now used on both the strain-free and the calorimetric thermometers.

The only essential modification in the construction of the strainfree type of thermometer is the change from unsealed to sealed thermometer tubes. This sealing eliminates the possibility of the condensation of moisture in the thermometer when it is being used at low temperatures.

The calorimetric construction has been modified in several particulars, notably, (I) the glass drying head has been found to be unnecessary if the thermometer case is tight and the initial drying has been complete; (2) a case made from German-silver tubing flattened into a sheath at one end has been substituted for the glass stem and the metal sheath previously used. This case, if constructed of German-silver tubing $0.75 \mathrm{~cm}$ in diameter and $0.02 \mathrm{~cm}$ thick, requires an immersion to a point only about $5 \mathrm{~cm}$ 
above the top of the winding in order that stem and lead conduction effects may be eliminated.

It is essential for the most accurate work that the winding of the calorimetric thermometer be free from strain. This freedom from strain may be attained by thoroughly annealing the wire before winding by winding, with very light tension, on a mica core' which is not less than $0.5 \mathrm{~mm}$ thick, so that the wire may not be unduly strained by bending around a sharp edge, and by flash-annealing the winding both before and after placing it in the case. Flash-annealing consists in connecting the winding for a few seconds across a voltage sufficiently high to heat the winding to a temperature of about $1000^{\circ} \mathrm{C}$ before the mica has time to heat above $600^{\circ} \mathrm{C}$.

A heating coil constructed along the lines of the calorimetric type of thermometer, with the substitution of a ribbon of resistance material for the platinum winding, has been found very effective and convenient for general laboratory use. Due to its small heat capacity and its large heat-transfer coefficient ( 0.07 watt $/ \mathrm{cm}^{2}$ per degree difference in temperature between the winding and the water bath), it is especially suited for use in temperature-controlled baths and for energy-measurement work.

WASHINGTON, September I8, I920. 